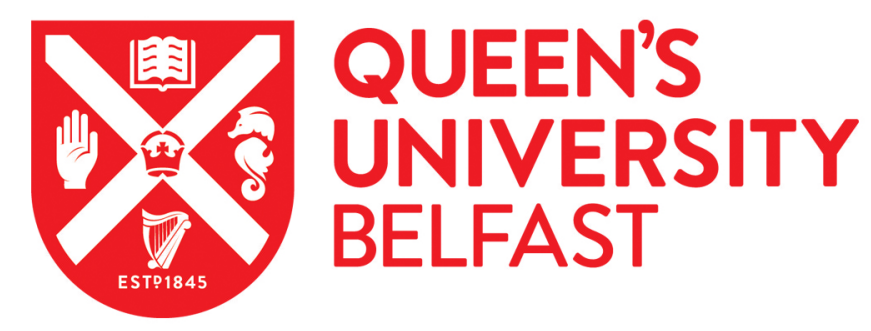

\title{
Psychological adjustment in patients post-curative treatment for oesophageal cancer: a longitudinal interview study
}

Graham-Wisener, L., Hanna, J., Collins, L., \& Dempster, M. (2019). Psychological adjustment in patients postcurative treatment for oesophageal cancer: a longitudinal interview study. Psychology and Health. https://doi.org/10.1080/08870446.2019.1579910

Published in:

Psychology and Health

Document Version:

Peer reviewed version

Queen's University Belfast - Research Portal:

Link to publication record in Queen's University Belfast Research Portal

Publisher rights

(c) 2019 Informa UK Limited, trading as Taylor \& Francis Group. This work is made available online in accordance with the publisher's policies. Please refer to any applicable terms of use of the publisher.

\section{General rights}

Copyright for the publications made accessible via the Queen's University Belfast Research Portal is retained by the author(s) and / or other copyright owners and it is a condition of accessing these publications that users recognise and abide by the legal requirements associated with these rights.

Take down policy

The Research Portal is Queen's institutional repository that provides access to Queen's research output. Every effort has been made to ensure that content in the Research Portal does not infringe any person's rights, or applicable UK laws. If you discover content in the Research Portal that you believe breaches copyright or violates any law, please contact openaccess@qub.ac.uk. 


\section{INTRODUCTION}

Oesophageal cancer is an increasingly prevalent disease (Cook, Chow \& Devesa, 2009), with the majority of patients eligible for curative treatment undergoing resection of the oesophagus with a demanding post-surgical recovery. Curative surgery often necessitates a post-operative change to eating behaviour, with common longer-term effects including nausea/vomiting, acid reflux, dysphagia and dumping syndrome, as well as a general loss of appetite and associated fatigue (Bouras et al, 2017; Greene et al, 2014). The impact of the diagnosis and curative treatment on patient reported outcome measures is well documented, with levels of psychological morbidity similar to head and neck cancers for both patient and carer (Graham, Dempster, McCorry, Donnelly \& Johnston, 2016; Dempster et al, 2012). However, the impact of oesophageal cancer is not usefully captured with a focus on outcome alone, which negates the process of adjusting to the condition. Rather, an understanding of post-treatment adjustment is essential in optimising survivorship for this clinical population.

The 'lived experience' of oesophageal cancer remains an under-researched area (Andreassen, Randers, Ternulf Nyhlin et al, 2007). The few qualitative studies which exist provide a wealth of information from the patient's perspective on the challenges of 'remapping the body' after surgery (Wainwright et al, 2007), the experience of dysphagia (Watt \& Whyte, 2003) and information needs (Andreassen, Randers, Naslund, et al, 2007; Mills \& Sullivan, 2000).

Quantitative research with oesophageal cancer patients and carers has identified illness perceptions, in line with the Common-Sense Model of Illness Representations (CSM; Cameron \& Leventhal, 2003), to be key predictors of psychological morbidity (Graham et al, 2016; Dempster et al, 2011). The CSM proposes individuals to access their lay explanations of illness in attempting to manage a health threat, which in turn guide goal-setting and coping behaviour. The previous research suggests several key beliefs as targets for intervention to enhance an oesophageal cancer patient or carer's psychological wellbeing; increase control beliefs, lessen focus on illness cause and set realistic expectations for consequences from the condition (Graham et al, 2016; Dempster et al, 2011). Though evidencing significant variance in levels of distress to be explained by illness beliefs, these studies provide limited understanding in relation to the content of beliefs, the differing levels of abstraction and the process by which beliefs are constructed or change over time.

Except for the referenced studies, there has not been a great deal of advancement in this area in the past decade. All published qualitative research is of a cross-sectional design, often exploring specific experiences. Longitudinal qualitative methods can suggest mechanisms involved in change, in particular over transitionary periods (Calman, Brunton, \& Molassiotis, 2013). The current study proposes to use serial interviews to elicit the process of adjustment for oesophageal cancer patients post-curative treatment, in particular the beliefs participants hold regarding their condition and how these are appraised against their experience.

\section{MATERIALS AND METHODS}

\section{Design}

A serial interview design, with an Interpretative Phenomenological Analysis approach (IPA; Smith, 1996). IPA as an approach aligns fittingly to the tenets of the CSM (Cameron \& Leventhal, 2003) in acknowledging the individual's constructed understanding of illness. The authors followed an idiographic, phenomenological approach

\section{Recruitment and Participants}


Oesophageal cancer patients were recruited from an Oesophageal Patient's Association meeting in Northern Ireland. Convenience sampling was used to include i) a past diagnosis of oesophageal cancer (curative pathway) and over 18 years of age. Although we aimed to recruit participants within 2 years of treatment end for whom adjustment to their condition is more salient, for pragmatic reasons some flexibility was used with this eligibility criterion. This sampling method was appropriate to IPA given the focus on studying divergence and convergence in small, homogenous samples (Brocki \& Wearden, 2006). Although there is no fixed sample size for IPA, there is a move towards the use of smaller sample sizes (Smith, \& Osborn, 2003).

The sample was composed of 6 oesophageal cancer patients (Table 1). Attrition was relatively high due to the period of recruitment being in the early post-treatment period, with 2 participants not undertaking the interview at the second time-point as a result of being too medically unwell.

\section{Procedure}

The study was approved by a Research Ethics Committee at Queen's University Belfast. Permission was granted from the Oesophageal Patients Association Northern Ireland committee. All participants provided written informed consent.

Semi-structured interviews were conducted by LGW, at the time a postgraduate researcher with training in qualitative research methods, face-to-face in either the patient's home $(n=4)$ or university $(\mathrm{n}=2)$ at the participant's preference. There had been no previous contact between the researcher and participants prior to the study. All participants were aware of the aims of the research before participation. The interview schedule included a number of open-ended, nondirected questions and minimal probes, developed from previous qualitative research in oesophageal cancer and the framework of the CSM (Cameron \& Leventhal, 2003). In line with the epistemological approach of IPA, the interview was allowed to progress along a course opened up by the participant rather than dictated by the interview schedule (Appendix I). The second interview was conducted at approximately 6 months follow-up utilising the same interview schedule. The interviews lasted a mean of 76 minutes at time one and 52 minutes at time two. Interviews were audio-recorded with all transcribed verbatim by the researcher (LGW). This study is reported according to COREQ guidelines (Tong, Sainsbury \& Craig, 2007).

\section{Data Analysis}

The interview transcripts were analysed using Smith and colleagues' (1999) analytic approach to Interpretative Phenomenological Analysis. The first transcript was read several times by the researcher (LGW) and the audio recording played back to facilitate familiarisation with the data. Initial thoughts and comments were then recorded, with no parameters on what could be commented on. The next reading of the transcript involved identifying emerging themes from the in-text annotations, which take the form of concise statements which align to psychological concepts. These were clustered and formed a list of second order themes. The second researcher (MD) checked the interpretation of themes from the transcript at this point. This process was repeated for all transcripts, at both time-points. The differences between the second order themes across transcripts were then assessed, with reference given to themes which appeared prevalent and articulate, with a strong link to data which exemplified the theme. From this a list of master themes was developed. In line with the approach recommended by Calman and colleagues (2013), the themes were assessed for their presence in the interviews at the second time-point. A final read through of the transcripts was undertaken to ensure the themes were grounded in the data. The development of second order and master themes (Appendix 2) was 
discussed with the second researcher (MD) and a clinician (JH) to increase validity; no changes were required.

\section{Reflexivity and Credibility of Analysis}

In acknowledgement of the role of interpretation in the theoretical basis of IPA, a reflective diary was kept by the researcher (LGW), a 29-year-old female, throughout data collection and analysis. The researcher approached the study with limited personal experience of oesophageal cancer, though familiarity with research literature and previous contact with oesophageal cancer patients, carers and clinicians. A largely negative preconception of the experience of participants was bracketed by curiosity in probing any participant comments on positive affirmations for more detail (McNair, Taft \& Hegarty, 2008).

As has been the case in various other IPA studies (e.g. Green, Payne \& Barnitt, 2004; Senior, Smith, Michie \& Marteau, 2002; Swift, Ashcroft, Tadd, Campbell \& Dieppe, 2002), the theoretical components of the CSM (Cameron \& Leventhal, 2003) helped inform the interview schedule, and imposed a framework on the analysis. However, the interview schedule was also kept open-ended with participants dedicating most of their time to describing their illness experience as a whole. As with Green and colleagues (2004), we would argue that we were open to the presence of additional theory which is indicated in the final narrative and we ensured all interpretations were grounded in data. According to Brocki and Wearden (2006), the majority of researchers would embark on the research process with an awareness of preexisting theory, with the CSM (Cameron \& Leventhal, 2003) the prominent theory in illness cognition research.

\section{RESULTS}

Acceptance of a new reality.

Realisation of a changed self. The participants' perception of a difference post-surgery was acutely realised in their change in appearance, leading to a disruption in body image and evoking feelings of age and fragility, with identity partly realised as feeling at home in one's body (Erikson, 1959). Michael recalls the shock at seeing himself after being discharged from hospital;

I looked in the mirror, and I didn't even recognise myself. I was old. If you know what I mean. I was looking at my grandfather. Just the way I'd lost weight, aged, my hair was all thin, you know. That worried me

One participant's weight loss after treatment resulted in body-related shame when reflecting on her previous self, the result of an adjustment in internalized social standards in relation to body image (Tracey \& Robins, 2004); 'That's taken hard as well, trying to change my body image. It's been really hard as well. You know, I still feel a big person mentally' (Gillian)

The participants perceived a relationship between weight gain and good health, this recovery model the opposite of the weight loss associated with the identity of the disease during progression. Weight gain was however experienced as a tentative balance.

In the initial post-treatment period, the participants held an acute model of illness with an expeditious return to levels of functioning before the onset of their illness appraised as indicating recovery. Work, for several participants, related to self-esteem and purpose, with cancer patients often regarding a return to work as a symbol of complete recovery (Spelten, Sprangers \& Verbeek, 2002). Liz returned to full time work shortly after her treatment ended. 
There is an understanding from Liz that this desire to return to work came at a point before she could form an understanding of the impact of her new condition, recalling 'I seemed to have boundless amounts of energy, I seemed to you know, but then I wasn't doing anything all day.' This required Liz to reduce her hours to part-time which was felt as a set-back.

Participants described an effortful process in fostering realistic expectations for recovery post treatment, with evidence of this emerging over time in becoming more attuned to the physiology of a changed body. Central to this was developing a more accurate model of illness in relation to more chronic physical symptoms.

I didn't honestly think that losing your oesophagus would, and part of your stomach, would have as big of an impact on your life. Didn't realise that. I knew it was big surgery when I was going for it. I knew that I could maybe only eat little and often afterwards but I didn't think that would go on forever and I didn't think as I say the losing of the oesophagus would affect your whole digestive system in the way that it does (Liz)

Recognition of chronic physical symptoms was understood in relation to their functional impact on the person, resulting in a sense of a 'changed' self; 'Fitness wise, from I had that, and had the treatment and the chemo, I don't know whether that will come back. Because I'm not the same, I can't do the same things as I did' (Melanie)

Participants experienced a greater understanding and acceptance of their new self-identity over time which was aptly referred to by one participant as 'the afterlife'. The majority of participants were able to not define themselves by the negative aspects of illness, related to poor psychological wellbeing as proposed by the Schema Enmeshment Model (Pincus \& Morley, 2001). Stephen illustrates this in his narrative; 'I don't look on it as a disability now, I just look on it that, that's me, just get on with it'. The integration of limitations into a positive self-concept was perceived as a time-consuming process, 'Give yourself time, you will get better. It will get easier if you give it time and you learn to live with it' (Stephen).

The change in self-concept related to a renegotiation of roles for the participants, with previously held responsibilities distributed to others and new roles emerging. With the lessening of existing responsibilities felt as a loss, participants adjusted to this change through a process of 'scaling back goals' (Carver \& Scheier, 2000) by prioritising what is still achievable. For Gareth there is acceptance that his new condition would not be conducive to the shift work of his previous job role. Work is no longer prioritised, and Gareth spends time during the day caring for his four young children which is valued by his wife, 'She's that used to me being there, whereas before whenever I was in work, it was nothing to her'.

Although acceptant of a changed self, the participants were motivated to be perceived as 'normal' by others and were able to navigate away from the identity of the cancer patient over time. Gillian illustrates this in her story when recalling her adult children's change in perception in the months following treatment, 'It's what I wanted. Things back to normal. They still see me as mum; they don't see me as mum's really ill. I don't want them to'.

The participants perceived themselves not as someone living with oesophageal cancer but rather as someone living with the side effects of treatment from oesophageal cancer. This movement away from the public identity of a 'sick person' was successful for most participants, an outcome bringing its own difficulties. The participants described those in their social network as not understanding their hidden health condition and social situations carried threat of a loss of the private self through needing to justify the reasons behind eating 
behaviour, 'they just expect then for you to go back to what you were. I try to explain that I would love to go back to what I was, but I can't' (Gillian). This was felt most acutely with strangers, with the distress associated with eating in restaurants resulting in avoidance behaviour,

So then when you go to a restaurant you've got this palaver to go through, 'Excuse me, would I be able to have a half portion?' And then they look at you as if you've horns growing out of your head (Liz)

Participants emphasised the role of food in making others feel welcome and suggest a cultured role for food, with resultant pressure from others in social situations who are trying to be hospitable. Participants recount several strategies to manage these situations, though often feeling obliged to accept the hospitability out of concern for upsetting or alienating themselves from their hosts, 'I wonder what they're gonna present for me to eat, can I eat it?' (Stephen).

Searching for Meaning. Altering the meaning of the illness experience is thought to aid adjustment, with views of the world more susceptible to change than self-image (Sharpe \& Curran, 2006). The search for meaning refers to both a) finding purpose and $b$ ) finding order (Thompson \& Janigian, 1988). Participants often engaged in benefit finding in relation to their oesophageal cancer diagnosis. A common focus was on prioritising non-materialistic goals, proposed to predict the perception of greater meaningfulness in life (Thompson \& Pitts, 1993). This is illustrated by Liz; 'It just puts an awful lot of things in life into perspective because that's when you say to yourself, money does not matter' (Liz)

The reprioritisation of goals occurred with participants becoming more appreciative of everyday actions being achievable, leading to a greater value being placed on minor things, 'just being able to get up' (Michael). Gillian's experience of oesophageal cancer is perceived as having allowed for closer family relationships and the building of resilience with prioritisation of undertaking everyday activities together as a family unit; 'As I say it has been hard on all of us. In different ways and at different times. We've got through it now. If anything, we are probably a closer family for it. And have time for each other more now'

The participants also reported finding new purpose as a result of their illness experience, the second component of meaning-making theory (Thompson \& Janigian, 1988). For most participants this was in respect to how they could improve the treatment and quality of life of other oesophageal cancer patients, providing a focus away from their own individual illness. With a shared identity came a sense of camaraderie, and an opportunity to exert control over how the disease impacted on others because of particular challenges they themselves had experienced. Stephen describes his motivation to attend patient association meetings where he helps empower other patients by providing reassurance and information;

I was very surprised how few of my friends and relatives crossed the door to see me. I was shocked. And you see, it's the 'Big C' factor. They're scared of it, they don't know what to expect, and it shocked me and made me realise that with people like me, you need to talk about cancer

The meaning of the event in terms of its impact can also be altered through strategies that allow for perspective taking (Sharpe \& Curran, 2006). Participants compared their oesophageal cancer experience to both events in their own life and with others, in concrete or hypothetical terms. This was viewed by the participants as a necessary process to facilitate a positive illness representation. In his story, Stephen discusses suffering from depression for years before the cancer which he reflects as being more severe, 'Now if I was to compare that and the cancer 
that I went through, if somebody said to me "which one would you do again if you had to?", I would say the cancer'. A shared identity is emphasised in relation to the cancer, with the depression in contrast felt as a very isolating experience. Participants engaged in perspective taking in relation to other oesophageal cancer patients and in a broader population sense as illustrated by Michael's experience soon after diagnosis;

I had come home and I was told that a girl I know had had a wee baby, and it died after nine or ten hours. And I had been saying to myself, you know when you get told you have cancer, why me? Well that is the first thing, why me? And then when I heard that, I said to myself, why not me?

\section{Relinquishing and harbouring control}

Clinicians as uniquely gifted. It can be adaptive for patients to relinquish control to 'powerful others' for management of their treatment outcome (Affleck, Tennen, Pfeiffer \& Fifield, 1987). This is in line with the reality-matching hypothesis (Christensen Smith, Turner \& Cundick, 1994) proposing beliefs in treatment control to be more appropriate where personal control is objectively less. The extent to which participants handed over control to the medical team was at times dramatic. This is illustrated in Gareth's account, where he accepts the treatment pathway readily without desire for any information on the mechanics of the surgery, 'let's fix it, what do you need me to do'. The participants in this study perceived clinicians to be highly competent, almost at times taking on a supernatural quality, 'the consultant was just out of this world' (Gillian).

Michael in his narrative emphasises particular characteristics of the clinicians involved in his care, around their years of experience and eminence in their field. This was linked to perceived control in relation to the success of the surgery and in relation to treatment control should a recurrence occur, 'there was someone responsible there'. The clinicians were described in a manner that made them 'known' as individuals to the participants.

Participants often recalled phrases utilised by clinical staff during their treatment pathway which appeared to initiate and form the basis of their control beliefs. Michael describes an encounter with his oncologist at an early stage in his treatment journey which challenged his previously held representation of oesophageal cancer;

You know, he says to me, you think that you're dying, don't you? I says, yes, I have cancer, I'm dying. He said you're not. He says I'm going to get this. So that made me feel a hell of a lot better

The conceptual understanding of surgery as removal of the cancer entity appeared to reduce thoughts of recurrence. In contrast, Melanie who has undergone curative treatment with definitive chemo-radiotherapy does not perceive the same degree of treatment control, despite understanding the potential for salvage surgery with recurrence. Melanie undertakes downwards social comparison with patients who have undergone surgery when attending a support group meeting;

I came out of there depressed because there was a girl who had the same cancer as me, and had the surgery in February. I said to myself, have I done the right thing? You know, because mine might come back but hers will not come back in the oesophagus because she has no oesophagus for it to come back in

Although participants overall held a belief in treatment control, several of the participants perceived the treatment as providing a temporal control to their cancer, with fear of recurrence a constant concern and effortful to dismiss. For these participants, a belief in the ability of 
clinicians to manage potential recurrence of cancer is attended to. Michael in his story uses tentative and non-committal language when discussing the treatment's success at both time points, not wishing to verbalise the term 'cure' either internally to himself or outwardly to others. Michael views himself as 'not having cancer at the moment' and focuses on living in the present, 'you keep it in the day'. This appears adaptive in avoiding concerns regarding longer term consequences, yet hampers his ability to commit to plans in the future.

Personal mastery over a new body. Although participants perceived a lack of personal control over the course of their illness, self-efficacy in controlling the everyday symptoms of their condition increased over time, symptoms considered to stem from the surgery rather than the cancer. Participants held different perceptions on the causation of symptoms from surgery, either resulting from fixing the body or as being residual from 'the damage done with the removal of it (the cancer)' (Michael). Participants experienced high symptom distress in relation to acid reflux, dumping syndrome, regurgitation and heartburn among other physical sequelae, described by the participants as 'nasty' and 'foul' with the body needing to be 'pacified'. Control over the symptoms was primarily perceived to be exerted through a necessitated change in eating behaviour and the use of medication.

The participants, as a collective, describe their new eating regime as centring on eating small portions, being mindful of eating and drinking together, avoiding eating late at night and avoiding foods high in fat or sugar content. Applying these general rules towards the successful management of symptoms is negotiated through a continual process of 'trial and error', with participants appraising their control of symptoms as progressing from the initial post-treatment period onwards. None of the participants recounted consistent control over the occurrence of symptoms; however, progress in the frequency of symptoms occurring was appraised as a valued goal, reflecting a recalibration to realistic goals alongside realisation of a changed self.

Several participants focused on their ability to manage symptoms or their consequences should they occur. This referred to use of medication and planning ahead so toileting facilities are accessible. Stephen in his narrative discusses how he understands 'what to do to tackle something' and references ready access to medication which is perceived as having efficacy in palliating his symptoms, 'at the end of the day, I know it's always there'. The less frequent occurrence of symptoms is therefore accepted in the knowledge that the symptom is identified and understood (often as dumping syndrome) and in the knowledge that 'you know it will pass'. For this participant over time there was a progression from management of the physical symptoms to managing the perceived side effects from medication. Stephen discusses the long-term effects of being on a sustained medication regime, and queries if as oesophageal cancer patients 'we should be taking a supplement to counteract' the effects of acid inhibitors or indigestion solutions.

Although participants appear to accomplish increased mastery over their necessitated eating regime in time, this is a challenge when eating in public outside the constructed routine of the home environment. Participants experienced social eating as challenging in relation to the desire to conform to a normative social identity, concern for disrupting the routine of others and in distracting from the careful monitoring required.

As a consequence of the necessitated change in eating behaviour to exert control over physical symptomatology, food is no longer enjoyed spontaneously by participants who carefully 'plan ahead' in relation to their eating and toileting needs. As a result, the participants describe a changed relationship with food post-treatment, 'food doesn't mean the same as what it used to' 
(Gillian). Participants felt this changed relationship with food as a loss, grieving what was once perceived as a reward and is now considered a task to be carefully managed and controlled. The psychological desire for food is present in participants' accounts at all time-points, and misaligned with their adjustment to what is accepted as a necessitated eating regime posttreatment. Michael describes the necessitated eating regime post-treatment as being unsatisfying, referring to 'these tiny pieces, these tiny meals'.

The changed relationship with food was felt acutely in the post-treatment period by the participants who received adjuvant therapy, having temporarily regained the ability to eat as before the onset of illness. The change in eating behaviour was experienced in conflict with a recovery model of illness. Liz illustrates this in her story, 'So when that tightened in I couldn't eat again so it was back to the old days of when I had the tumour. Psychologically that was a wee bit...'. Liz however clearly differentiates between her current eating behaviour and her experience during onset of illness, emphasising that she has maintained her mechanical ability to eat.

Acceptance of the necessitated change in eating behaviour post-treatment was experienced as an effortful process of adjustment, breaking from what had previously been an automated activity.

I think once you get doing that more repetitively, time and time again, it just comes automatic. That there has probably been the hardest. For the last [number of] years I've just ate, drank, how I wanted and when I wanted. And now there has just been this last three years (Gillian)

Bodily feedback in the form of hunger and satiety were experienced by the participants as at odds with their limited capacity for food in the early post-treatment period. Over time participants became more attuned to their body. Michael evidences this at the second time point,

'I'd eat it, knowing that I was going to be sick. Now I don't. In fact, my body tells me now, I know when I've had enough'.

For several participants, their desire for particular foods changed. This was related both to a change in sensory feedback and also in relation to associations made between a particular food and previous negative experience. In her story, Gillian describes loss of a desire for foods she used to enjoy which she relates to the smell of the food. There is also an adjustment in a new desire for foods;

It's just the taste, I don't know what's happened, whether it's through the chemo as well or whether my stomach is higher up and been moved, but there have been tomatoes and lettuce, spinach, things that I would have had a little of but not a desire for. I just love them now. So that psychologically is really weird

Although the participant's relationship with food changed, food still retained some of the same associations for the participants, notably as being nourishing and connected with good health. The body's altered capacity for food however resulted in the reassuring nature of these roles not being realised. Gillian refers to food as ' $a$ comfort blanket'. Although the disparity is recognised, Gillian discusses enjoying a coffee at the follow-up interview to instil a similar feeling.

\section{Understanding of illness}


Knowledge as empowering or threatening. The participants appraised information as being both empowering and threatening, depending on the content and timing of the exchange. Throughout diagnosis, active treatment and follow-up, the patients struggled to assert control over what information was communicated to themselves and their loved ones. This was experienced as destabilising as it was considered a part of their care which patients should be able to control and with the potential to disrupt the participants' feeling of equilibrium.

Information on prognosis and the technical aspects of treatment were experienced as particularly distressing.

I should have been able to say to him that I don't want to know. Just go on with it, but by law they have to tell you. Everything. Like the fella told me about the operation, he took great enjoyment out of going through every part of it (Michael)

With oesophageal cancer necessitating major surgery for most participants, distress was experienced in relation to the potential risks from the procedure, perceived as 'intrusive' in nature and unsettling bodily autonomy. Participants minimised this threat by avoiding information relating to surgery, the surgery conjuring images of frailty as illustrated by Michael, 'just knowing that I've been in that position. Just how close...to death you actually were'.

The patients often protected their loved ones from information regarding the disease. Keeping this confidence was felt as an oppressive weight, enforcing a feeling of isolation. In Michael's narrative, there are multiple levels of going 'public' with the diagnosis, the hardest being 'plucking up the courage' to reveal the diagnosis to his adult son. In relation to loved ones, there is emphasis on what information they 'had to know', with patients perceiving a lack of desire for information by the carer. In contrast, at the second time-point Michael experiences others to have undertaken the protective role, avoiding discussion of cancers or other serious illnesses in front of him at a stage where he is ready to talk more openly. This reciprocal buffering has been evidenced in various cancer populations (Hilton, Crawford \& Tarko, 2000).

In Gareth's story he describes how with several young children, it was important to maintain a sense of normality. The children are perceived as too young to be informed of the diagnosis with Gareth and his wife fostering an alternative explanation for his time away from home and recovery, 'I fell off a wall and got damaged and they had to fix me'.

Participants perceived information as empowering if it was seen to increase their self-efficacy in exerting control over their condition. The usefulness of information in giving the patient an illness trajectory on which to appraise their experience was emphasised. Participants experienced difficulty in accessing this information themselves in isolation from information perceived as threatening. Gareth illustrates this in his narrative, 'I Googled it, read for about five minutes, closed it. Never ever Googled it again. Never ever will Google it again. It's the worst thing I could have done'. Participants therefore relied on 'expert' others to relay information to them.

Other oesophageal cancer patient peers were perceived as having a special role in imparting knowledge. This contact was not perceived to be adaptive in the pre-treatment phase where it was important to recognise that 'no two cancers are exactly the same' (Michael) in order to avoid social comparisons in relation to prognosis. Rather the importance of a shared identity was experienced as valuable in the post-treatment period in fostering a realistic illness trajectory. Information from patient peers was prioritised in relation to their unique sense of 
'knowing' which is separate to that of clinical staff or the lay person. Coming into contact with patient peers was experienced as instilling feelings of togetherness and reassurance, 'What I' $m$ going through, it's not just me, there is somebody else going through the same thing' (Michael). Contact with peers allowed for symptom checking and advice on symptom management. Stephen recounts contact with a peer with whom he would 'compare notes'.

The presence of the patient peers themselves led to positive social comparison for most of the participants, instilling feelings of hope and longevity. As Gillian illustrates in her narrative; 'That's my long term. Just think of all the other people. That gives me a lot of hope and a lot of, taking the stress out of it. Not to stress about the long term because there's all these people'

Contact with patient peers can also be appraised negatively. Melanie in her narrative describes joining a group for oesophageal cancer patients on social media. Perceiving the patients as having a shared identity yet having undergone an alternative curative treatment to herself, surgery as opposed to chemo-radiotherapy, Melanie experienced feelings of isolation and regret. Similarly, Gillian discusses an acquaintance, who she appraises as having less severe cognitive impairment, felt in relation to the reduced loss of activities once enjoyed;

Um, but you know, she is back to work, she has her, I just couldn't even think of work. My memory because of the second lot of chemo, I just don't know. My concentration is horrendous. There's all small things but makes up an impact on your life that you don't realise

Moving away from self-blame. The participants held complex and rich explanatory models for their oesophageal cancer. These explanatory models became more ingrained over time, with participants in the early period after diagnosis attempting not to consider the cause. All the participants perceived a cause of illness with an internal locus of control to some extent. Their explanatory model however was developed over time to accommodate this without inducing self-blame, established as relating to poor psychological outcome (Friedman et al, 2007) and proposed to encompass the two constructs of behavioural and characterological self-blame (Janoff-Bulman, 1979).

Several participants held explanatory models with a congenital origin, around a tendency towards issues with their stomach and acid reflux. In Stephen's story he describes, 'I have always said my stomach would not have been one of my better parts' and rationalises that 'In hindsight, yes I would have been a candidate for it, put it like that'. Gareth in his narrative describes attribution to heartburn, a symptom his father and brothers also suffer from. In addition to perceiving a congenital influence. Liz describes a family history of Barrett's Oesophagus, 'I did have an underlying problem always with my oesophagus, so you know...it perhaps wasn't inevitable it was going to happen but there was a chance or a likelihood that it could'. In relation to the precipitating factor, Liz rationalises that 'I don't think and I don't blame myself in any way for it because I wasn't a smoker'. In not attributing self-blame, the participants are not preoccupied by the cause of their cancer.

\section{DISCUSSION}

This study is the first to longitudinally examine the process of adjustment for oesophageal cancer patients post-curative treatment. The serial interview design of the research allowed a complex and effortful process of adjustment to emerge. As with previous research (see Graham \& Wikman 2016, for review), the consequences of living with post-treatment oesophageal cancer were most acutely felt in relation to perceived side effects from a changed digestive system, resulting in disruption for the patient and family unit. The process of adjustment focused on recognising and accepting a changed self, fostering control beliefs over the course 
of the illness and physical sequelae, searching for meaning, developing illness coherence and moving away from self-blame.

Recognition and acceptance of the patient's changed-self appeared a key milestone in post treatment adjustment. With a long-term impact on physical functioning in oesophageal cancer (Deschamps, Nichols, Cassivi, Allen \& Pairolero, 2005), the participants' inability to achieve realistic goals for physical recovery post-treatment were experienced as set-backs with associated distress. The current study suggests information need to change across the illness trajectory, with a role for information on symptom management in the post-operative period to allow for accurate recognition of symptoms and a realistic illness trajectory on which experience may be appraised. This is supported by a recent Delphi study to identify topics to be addressed at initial follow-up consultation after oesophageal cancer surgery (Jacobs, Henselmans et al, 2014). An assessment of patient information leaflets provided by UK NHS Trusts evidences the current inconsistency of information included on the identified domains (Blencowe et al, 2015).

Participants in the current study experienced difficulty isolating this information from undesired information in their own retrieval efforts post-treatment. Undesired information in the active treatment/early post-operative period included detailed information about the more technical aspects of their surgery. This evoked a feeling of vulnerability which participants did not perceive as helpful in building a positive representation of illness and a belief in treatment control. This mirrors the broader literature (Lagarde et al, 2008), where oesophageal cancer patients during active treatment and in the initial post-treatment period emphasised need for more positive information (Mills \& Sullivan, 2000). A patient-centred approach to information provision in oesophageal cancer is needed, with attention afforded to individual preferences for information content and timing. One solution is to develop methods of empowering patients to ask questions at various stages of the treatment pathway, for example through use of a question prompt-sheet (Jacobs and colleagues (2016).

Protective buffering was evident in the current study, referring to a dysfunctional communication strategy with the cancer patient or carer withholding or hiding information and thoughts about the condition from their partner in addition to acquiescing to avoid conflict (Hagedoorn et al, 2000). This was experienced as an isolating experience. Protective buffering results in both intrapersonal and interpersonal effects (Langer, Brown \& Syrjala, 2009; Traa, Vries, Bodenmann \& Oudsten, 2014), and previous research has evidenced interpersonal coping to explain variance in distress in both oesophageal cancer patients and carers (Graham et al, 2016; Dempster et al, 2011b; 2012). This suggests value in developing psychological interventions delivered at the level of the dyad and focusing on communication, suggested in a recent systematic review as likely to have a broader impact on outcome (Regan et al, 2015).

Several participants reported holding unrealistic expectations for recovery despite receiving information from health care professionals. With illness perceptions known to be relatively consistent across time (Dempster et al, 2011a; Graham et al, 2016), psychological intervention to help foster and accept a more chronic model of the longer-term effects of the cancer and treatment is likely warranted. Of note, control cognitions appeared adaptive in relation to perceiving the clinical team as exerting control over the course of the illness, and the patient as exerting control over the everyday symptoms from their condition. The use of Cognitive Behavioural Therapy (Butler, Chapman, Forman, \& Beck, 2006) to challenge maladaptive illness representations and foster more realistic beliefs has been successful in various clinical populations leading to improved psychological wellbeing (e.g. Siemonsma et al, 2013). For the 
oesophageal cancer patient, fostering realistic expectations in accepting an on-going process of trial and error towards effective symptom management would be important. A useful example is a web-based self-management intervention for cancer patients (Willems et al, 2017), successfully instilling self-efficacy/personal control beliefs through the provision of individualised, disease specific information, through use of Cognitive Behavioural Therapy (CBT) monitoring and setting realistic goals, and the use of fellow patients and clinicians as models to provide information on expectations and discuss problem-solving techniques for ongoing symptom management.

Lastly, participants in the current study reported engaging in strategies to change the meaning of the oesophageal cancer experience. This was both in relation to perspective taking (in relation to self and others), in revaluating and prioritising goals which are achievable within the restrictions of the new way of life and in finding new strengths. This is a similar theme to have emerged in previous research with oesophageal cancer patients (Clarke, McCorry \& Dempster, 2011) and the current study evidences that this process can occur at an early stage in the post-treatment period. There are a number of positive psychology interventions (see Casellas-Grau, Font, \& Vives, 2014 for review) which help to foster posttraumatic growth in cancer patients, with effective interventions focused more specifically on encouraging meaning-making (Coward \& Kahn, 2005; Lee, Cohen, Edgar, Laizner, \& Gagnon, 2006). This would appear of particular benefit to oesophageal cancer patients given the significance of the event in challenging pre-existing beliefs in relation to global meaning of how the world works.

There are several limitations to the study. Firstly in keeping with the tenets of IPA, this study aimed to produce a detailed analysis of the narratives of a small number of patients with generalisations to a broader population approached with caution (Flowers, Smith, Sheeran, \& Beail, 1997). There is however discussion in the literature over the extent to which insights from IPA studies are generalisable (Brocki \& Wearden, 2006), with Smith (1999) asserting validity of a theory from its applicability within an IPA study. Similarly this study would appear to further evidence the relevance of the CSM (Cameron \& Leventhal, 2003) to understanding adjustment to oesophageal cancer, and provides insight as to the development of illness beliefs. Secondly, the sample recruited were young so it may be argued that the process of adjustment for these patients may be different, indeed the family impact of the patient's condition is one area which may be more salient. This does however give insight into the heightened challenges faced by younger oesophageal cancer dyads who are becoming more prevalent (Camargo et al, 2011; Donohoe, MacGillycuddy \& Reynolds, 2011). Lastly, in line with previous longitudinal qualitative research by Calman and colleagues (2013), the themes were generated and then assessed for their presence in the interviews at the second time-point. An alternative may be to undertake a separate analysis for evidence of themes for each time point. This was not conducive to the current study given that the patients were not all at a specific time-point post-diagnosis, with the recruitment of a highly homogenous sample a consideration for future IPA research applying a longitudinal design.

\section{CONCLUSION}

In conclusion, this study provides detail on the lived experience of oesophageal cancer patients using a longitudinal design, a novel approach within oesophageal cancer and addressing recommendations in the general cancer literature to consider experiences longitudinally (Jarrett et al, 2013). The implementation of the NHS Cancer Plan (2000) is supported for oesophageal cancer through the publication of Improving Outcomes Guidance in Upper Gastro-Intestinal Cancer (2000) which makes specific reference to the provision of timely psychological support to both Upper GI cancer patients and their family carers. Despite these policy 
recommendations, the best model of care for providing psychological support for oesophageal cancer patients and carers is unknown (Lordick, Mariette, Haustermans, Obermannova \& Arnold, 2016). The findings of the current study will be of use to health and social care clinicians and providers in assessing how best to support this clinical population after active treatment end. In particular, we identify several key components which appear to facilitate adjustment for this dyad in line with the Common-Sense Model of Illness Representations (Cameron \& Leventhal, 2003).

\section{ACKNOWLEDGEMENTS}

We would like to thank the Oesophageal Patients Association Northern Ireland for their support of this research and the participants who were so generous with their time.

\section{FUNDING}

This work was supported by a Department of Employment and Learning Northern Ireland $\mathrm{PhD}$ Studentship.

\section{DECLARATION OF CONFLICTING INTERESTS}

The Authors declare that there is no conflict of interest.

\section{REFERENCES}

Affleck, G., Tennen, H., Pfeiffer, C., \& Fifield, J. (1987). Appraisals of control and predictability in adapting to a chronic disease. Journal of Personality \& Social Psychology, 53(2), 273-279.

Andreassen, S., Randers, I., Näslund, E., Stockeld, D., \& Mattiasson, A. C. (2007). Information needs following a diagnosis of oesophageal cancer; self-perceived information needs of patients and family members compared with the perceptions of healthcare professionals: a pilot study. European journal of cancer care, 16(3), 277-285.

Andreassen, S., Randers, I., Ternulf Nyhlin, K., \& Mattiasson, A. C. (2007). A metaanalysis of qualitative studies on living with oesophageal and clinically similar forms of cancer, 
seen from the perspective of patients and family members. International Journal of Qualitative Studies on Health and Well-being, 2(2), 114-127.

Blencowe, N. S., Strong, S., McNair, A. G. K., Howes, N., Elliot, J., Avery, K. N., \& Blazeby, J. M. (2015). Assessing the quality of written information provision for surgical procedures: a case study in oesophagectomy. BMJ open, 5(10), 1-9. doi: 10.1136/bmjopen2015-008536

Bouras, G., Markar, S. R., Burns, E. M., Huddy, J. R., Bottle, A., Athanasiou, T., ... \& Hanna, G. B. (2017). The psychological impact of symptoms related to esophagogastric cancer resection presenting in primary care: A national linked database study. European Journal of Surgical Oncology (EJSO), 43(2), 454-460.

Brocki, J. M., \& Wearden, A. J. (2006). A critical evaluation of the use of interpretative phenomenological analysis (IPA) in health psychology. Psychology and health, 21(1), 87-108.

Butler, A. C., Chapman, J. E., Forman, E. M., \& Beck, A. T. (2006). The empirical status of cognitive-behavioral therapy: a review of meta-analyses. Clinical psychology review, 26(1), 17-31.

Calman, L., Brunton, L., \& Molassiotis, A. (2013). Developing longitudinal qualitative designs: lessons learned and recommendations for health services research. BMC medical research methodology, 13(1), 14.

Camargo, M,C., Anderson, W, F., King, J, B., Correa, P., Thomas, C, C., Rosenberg, P, S., ... \& Rabkin, C. S. (2011). Divergent trends for gastric cancer incidence by anatomical subsite in US adults. Gut, 60(2), 1644-1649

Cameron, L.D.,\& Leventhal, H. (Eds.) (2003). The self-regulation of health and illness behavior. New York, NY: Routledge

Caplan, G. (Ed.) (1974). Support systems and community mental health: Lectures on concept development. Pasadena, CA: Behavioral Publications. 
Carver, C. S., \& Scheier, M. F. (2000). Scaling back goals and recalibration of the affect system are processes in normal adaptive self-regulation: Understanding "response shift" phenomena. Social Science \& Medicine, 50(12), 1715-1722

Casellas-Grau, A., Font, A., \& Vives, J. (2014). Positive psychology interventions in breast cancer. A systematic review. Psycho-Oncology, 23(1), 9-19.

Christensen, A. J., Smith, T. W., Turner, C. W., \& Cundick, K. E. (1994). Patient adherence and adjustment in renal dialysis: a person $\mathrm{x}$ treatment interactive approach. Journal of Behavioral Medicine, 17(6), 549-566.

Cook, M. B., Chow, W. H., \& Devesa, S. S. (2009). Oesophageal cancer incidence in the United States by race, sex, and histologic type, 1977-2005. British journal of cancer, 101(5), 855-859.

Coward, D. D., \& Kahn, D. L. (2005). Transcending breast cancer: making meaning from diagnosis and treatment. Journal of Holistic Nursing, 23(3), 264-283.

Delormier, T., Frohlich, K. L., \& Potvin, L. (2009). Food and eating as social practiceunderstanding eating patterns as social phenomena and implications for public health. Sociology of health \& illness, 31(2), 215-228.

Dempster, M., McCorry, N.K., Brennan, E., Donnelly, M., Murray, L.J., \& Johnston, B.T. (2011a). Do changes in illness perceptions predict changes in psychological distress among oesophageal cancer survivors? Journal of Health Psychology, 16(3):500-509.

Dempster, M., McCorry, N. K., Brennan, E., Donnelly, M., Murray, L. J., \& Johnston, B. T. (2011b). Psychological distress among family carers of oesophageal cancer survivors: the role of illness cognitions and coping. Psycho-Oncology, 20(7), 698-705.

Dempster, M., McCorry, N.K., Brennan, E., Donnelly, M., Murray, L, \& Johnston, B.T. (2012). Psychological distress among survivors of esophageal cancer: the role of illness cognitions and coping. Diseases of the Esophagus, 25(3):222-227. 
Deschamps, C., Nichols III, F.C, Cassivi, S.D., Allen, M.S., \& Pairolero, P.C. (2005). Long-term function and quality of life after esophageal resection for cancer and Barrett's. Surgical Clinics of North America, 85(3),649-656.

Donohoe, C. L., MacGillycuddy, E., \& Reynolds, J. V. (2011). The impact of young age on outcomes in esophageal and junctional cancer. Diseases of the Esophagus, 24(8), 560568.

Erikson, E. H. (1959). Identity and the life cycle: Selected papers. Psychological issues, $1,1-171$.

Flowers, P., Smith, J.A., Sheeran, P., \& Beail, N. (1998). 'Coming out' and sexual debut: understanding the social context of HIV risk-related behaviour. Journal of Community \& Applied Social Psychology, 8(6), 409-421.

Friedman, L. C., Romero, C., Elledge, R., Chang, J., Kalidas, M., Dulay, M. F., ... \& Osborne, C. K. (2007). Attribution of blame, self-forgiving attitude and psychological adjustment in women with breast cancer. Journal of behavioral medicine, 30(4), 351-357.

Graham, L., Dempster, M., McCorry, N. K., Donnelly, M., \& Johnston, B. T. (2016). Change in psychological distress in longer-term oesophageal cancer carers: are clusters of illness perception change a useful determinant?. Psycho-Oncology, 25(6), 663-669.

Graham, L., \& Wikman, A. (2016). Toward improved survivorship: supportive care needs of esophageal cancer patients, a literature review. Diseases of the Esophagus, 29(8), 1081-1089.

Greene, C. L., DeMeester, S. R., Worrell, S. G., Oh, D. S., Hagen, J. A., \& DeMeester, T. R. (2014). Alimentary satisfaction, gastrointestinal symptoms, and quality of life 10 or more years after esophagectomy with gastric pull-up. The Journal of thoracic and cardiovascular surgery, 147(3), 909-914 
Green, A., Payne, S., \& Barnitt, R. (2004). Illness representations among people with non-epileptic seizures attending a neuropsychiatry clinic: a qualitative study based on the selfregulation model. Seizure, 13(5), 331-339.

Hagedoorn, M., Kuijer, R. G., Buunk, B. P., DeJong, G. M., Wobbes, T., \& Sanderman, R. (2000). Marital satisfaction in patients with cancer: Does support from intimate partners benefit those who need it most?. Health Psychology, 19(3), 274.

Harris K.A. (1998) The informational needs of patients with cancer and their families. Cancer Practice 6(1), 39-46

Hilton, B. A., Crawford, J. A., \& Tarko, M. A. (2000). Men's perspectives on individual and family coping with their wives' breast cancer and chemotherapy. Western journal of nursing research, 22(4), 438-459.

Jacobs, M., Henselmans, I., Macefield, R. C., Blencowe, N. S., Smets, E. M. A., de Haes, J. C. J. M., ... \& van Berge Henegouwen, M. I. (2014). Delphi survey to identify topics to be addressed at the initial follow-up consultation after oesophageal cancer surgery. British Journal of Surgery, 101(13), 1692-1701

Jacobs, M., Henselmans, I., Arts, D. L., Koppel, M., Gisbertz, S. S., Lagarde, S. M., ... \& Smets, E. M. A. (2016). Development and feasibility of a web-based question prompt sheet to support information provision of health-related quality of life topics after oesophageal cancer surgery. European journal of cancer care. doi: 10.1111/ecc.12593.

Janoff-Bulman, R. (1979). Characterological versus behavioral self-blame: inquiries into depression and rape. Journal of personality and social psychology, 37(10), 1798-1809.

Jarrett, N., Scott, I., Addington-Hall, J., Amir, Z., Brearley, S., Hodges, L., ... \& Siller, C. (2013). Informing future research priorities into the psychological and social problems faced by cancer survivors: a rapid review and synthesis of the literature. European Journal of Oncology Nursing, 17(5), 510-520. 
Lagarde, S.M., Franssen, S.J., van Werven, J.R., Smets, E.M., Tran, T.K., Tilanus, H.W., et al. (2008). Patient preferences for the disclosure of prognosis after esophagectomy for cancer with curative intent. Annals of Surgical Oncology, 15(11), 3289-3298.

Langer, S. L., Brown, J. D., \& Syrjala, K. L. (2009). Intrapersonal and interpersonal consequences of protective buffering among cancer patients and caregivers. Cancer, 115(S18), 4311-4325.

Lee, V., Cohen, S. R., Edgar, L., Laizner, A. M., \& Gagnon, A. J. (2006). Meaningmaking and psychological adjustment to cancer: development of an intervention and pilot results. Oncology nursing forum, 33( 2), 291-302

Mills, M. E., \& Sullivan, K. (2000). Patients with operable oesophageal cancer: their experience of information-giving in a regional thoracic unit. Journal of Clinical Nursing, $9(2)$, 236-246.

McCorry, N. K., Dempster, M., Clarke, C., \& Doyle, R. (2009). Adjusting to life after esophagectomy: the experience of survivors and carers. Qualitative Health Research, 19(10), 1485-1494.

McNair, R., Taft, A., \& Hegarty, K. (2008). Using reflexivity to enhance in-depth interviewing skills for the clinician researcher. BMC Medical Research Methodology, 8(1), 73

Pincus, T., \& Morley, S. (2001). Cognitive-processing bias in chronic pain: A review and integration. Psychological Bulletin, 127, 599-617.

Regan, T. W., Lambert, S. D., Kelly, B., Falconier, M., Kissane, D., \& Levesque, J. V. (2015). Couples coping with cancer: exploration of theoretical frameworks from dyadic studies. Psycho-Oncology, 24(12), 1605-1617.

Senior, V., Smith, J. A., Michie, S., \& Marteau, T. M. (2002). Making sense of risk: an interpretative phenomenological analysis of vulnerability to heart disease. Journal of health psychology, 7(2), 157-168. 
Sharpe, L., \& Curran, L. (2006). Understanding the process of adjustment to illness. Social science \& medicine, 62(5), 1153-1166.

Siemonsma, P. C., Stuive, I., Roorda, L. D., Vollebregt, J. A., Walker, M. F., Lankhorst, G. J., \& Lettinga, A. T. (2013). Cognitive treatment of illness perceptions in patients with chronic low back pain: a randomized controlled trial. Physical therapy, 93(4), 435-448.

Smith, J. A., \& Osborn, M. (2003). Interpretative phenomenological analysis. In Smith, J. A. (Ed.) Qualitative Psychology: A practical guide to research methods, (pp. 53-80). London: Sage Publications.

Smith, J., Jarman, M., \& Osborn, M. (1999). Doing interpretive phenomenological analysis. In Murray, M \& Chamberlain, K (Eds.) Qualitative health psychology. London: Sage

Smith, J. A. (1996). Beyond the divide between cognition and discourse: Using interpretative phenomenological analysis in health psychology. Psychology and health, 11(2), 261-271.

Spelten, E. R., Sprangers, M. A., \& Verbeek, J. H. (2002). Factors reported to influence the return to work of cancer survivors: a literature review. Psycho-Oncology, 11(2), 124-131.

Sprangers, M., \& Schwartz, C. (1999). Integrating response shift into health-related quality of life research: A theoretical model. Social Science \& Medicine, 48(11), 1507-1515

Stenberg, U., Ruland, C. M., \& Miaskowski, C. (2010). Review of the literature on the effects of caring for a patient with cancer. Psycho-oncology, 19(10), 1013-1025.

Swift, T. L., Ashcroft, R. E., Tadd, W., Campbell, A. V., \& Dieppe, P. A. (2002). Living well through chronic illness: the relevance of virtue theory to patients with chronic osteoarthritis. Arthritis Care \& Research, 47(5), 474-478.

Thompson, S. C., \& Janigian, A. S. (1988). Life schemes: A framework for understanding the search for meaning. Journal of social and clinical psychology, 7(2-3), 260280. 
Thompson, S. C., \& Pitts, J. (1994). Factors relating to a person's ability to find meaning after a diagnosis of cancer. Journal of Psychosocial Oncology, 11(3), 1-21.

Tong, A., Sainsbury, P., \& Craig, J. (2007). Consolidated criteria for reporting qualitative research (COREQ): a 32-item checklist for interviews and focus groups. International journal for quality in health care, 19(6), 349-357.

Traa, M. J., De Vries, J., Bodenmann, G., \& Den Oudsten, B. L. (2015). Dyadic coping and relationship functioning in couples coping with cancer: A systematic review. British journal of health psychology, 20(1), 85-114.

Tracy, J. L., \& Robins, R. W. (2004). " Putting the Self Into Self-Conscious Emotions: A Theoretical Model". Psychological Inquiry, 15(2), 103-125.

Wainwright, D., Donovan, J.L., Kavadas, V., Cramer, H., \& Blazeby, J.M. (2007). Remapping the body: learning to eat again after surgery for esophageal cancer. Qualitative Health Research, 17(6), 759-771.

Watt, E., \& Whyte, M.N. (2003). The experience of dysphagia and its effect on the quality of life of patients with oesophageal cancer. European Journal of Cancer Care, 12(2), 183-193. 
Willems, R. A., Lechner, L., Verboon, P., Mesters, I., Kanera, I. M., \& Bolman, C. A. (2017). Working mechanisms of a web-based self-management intervention for cancer survivors: a randomised controlled trial. Psychology \& Health, 32(5), 605-625.

Table 1. Participant Characteristics

\begin{tabular}{|c|c|c|c|c|c|}
\hline Pseudonym & Age & Gender & Ethnicity & Occupation & $\begin{array}{c}\text { Years since } \\
\text { surgery }\end{array}$ \\
\hline Stephen & 68 & $\mathrm{M}$ & White Caucasian & Retired & 6 \\
\hline Michael & 52 & $\mathrm{M}$ & White Caucasian & $\begin{array}{l}\text { Medically } \\
\text { retired }\end{array}$ & 2 \\
\hline Gillian & 48 & $\mathrm{~F}$ & White Caucasian & Homemaker & 2 \\
\hline Melanie & 52 & $\mathrm{~F}$ & White Caucasian & $\begin{array}{c}\text { Employed } \\
\text { (illness leave) }\end{array}$ & $1 *$ \\
\hline Liz & 46 & $\mathrm{~F}$ & White Caucasian & Employed & 1 \\
\hline Gareth & 34 & $\mathrm{M}$ & White Caucasian & $\begin{array}{c}\text { Employed } \\
\text { (illness leave) }\end{array}$ & 0.5 \\
\hline
\end{tabular}

